\title{
HYDRAULIC CHARACTERISTICS OF PLOW PAN CONSTRUCTED SANDY PADDY SOIL BY ADDING FLY ASH
}

\author{
YANG WeI ${ }^{1,2 *}$ NAN Lu ${ }^{1,2}$, Bo YAN ${ }^{1,2}$ AND GANG $\mathrm{LI}^{1,2}$ \\ Shaanxi Provincial Land Engineering Construction Group Co. Ltd., Xi'an 710075, China
}

Keywords: Fly ash, Paddy soil, Artificial plow pan, Soil water

\begin{abstract}
The feasibility of mixing fly ash to sandy soil to build the artificial plow pan of paddy soil in the Yellow River beach was explored. Water infiltration characteristics, saturated hydraulic conductivity, saturated water content and water storage capacity of the artificial plow pan were measured by using laboratory column tests. The results showed that under the same bulk density, when the amount of fly ash increased, the movement rate of the plow pan wetting front, the infiltration rate and the saturated hydraulic conductivity were decreased, then the water content and water storage of the soil layer increased. When the application amount of the fly ash was the same, and when the compaction weight decreased, the wetting front movement rate and saturated hydraulic conductivity increased and the soil water content and water storage capacity decreased. Mixing of fly ash with sand at a ratio of 1:3 (by weight) was found to be ideal for making an artificial of plow pan having bulk density of $1.7 \mathrm{~g} / \mathrm{cm}^{3}$.
\end{abstract}

\section{Introduction}

Innovating land consolidation methods and optimizing agricultural planting structure are effective ways to improve land utilization efficiency (Dunea and Dinca 2014, Niels 2015, Tang et al. 2017). The development and consolidation of beach land can effectively improve the utilization of land resources and achieve a dynamic balance of total cultivated land, thus ensuring regional economic and social development (Wang et al. 2001). The severe westward movement of the Yellow River channel in the Hancheng City of Shaanxi Province of China continuously causing high shore and beach areas to collapse. Collapse of large areas of beach land into the river, and the pressure on flood control every year is seriously endangering the lives and property of people along the coast. In order to improve the river regime, prevent continuous collapse, river erosion, and protect villages along the river and cultivated land, the local government has changed the river water potential through control projects, thus forming a large area of beach land.

The Yellow River beach is rich in water resources and can be developed to wetland agriculture. According to the investigation of local light and heat resource conditions, and comprehensive groundwater depth, rice can be grown in this region. However, due to the sandy soil type in the beach land, direct planting is likely to result in water and fertilizer leakage. Therefore, if it is possible to artificially construct a plow pan which might support retention of water to achieve high crop yield.

Fly ash is a waste discharged from local coal, having small particle size, high activity and strong adsorption capacity (Maebana et al. 2013, An et al. 2016, Gao et al. 2019). There are many coal-fired power plants in this region, and the output of fly ash is increasing every year. A large amount of land is occupied by fly ash, destroying the ecological environment. Use of these fly ash to construct the plow pan layer might help to solve the storage problem of huge amount of fly ash, as well as help rice cultivation in this region.

\footnotetext{
*Author for correspondence: <weiyang1120@163.com>. ${ }^{1}$ Key Laboratory of Degraded and Unused Land Consolidation Engineering, the Ministry of Natural and Resources, Xi' an 710075, China. ${ }^{2}$ Shaanxi Provincial Land Consolidation Engineering Technology Research Center, Xi’an 710075, China.
} 
Fly ash has the potential to improve soil physical, chemical and biological properties (Ukwattage et al. 2013, Medina et al. 2015). At present, there are two aspects of the application of fly ash in agriculture. Firstly, fly ash is rich in $\mathrm{K}, \mathrm{Si}, \mathrm{Ca}, \mathrm{Mg}$ and a certain amount of trace elements and is used as a compound fertilizer additive (Liu and Liao 1997, Qiu and Hlavacek 2010, Sano et al. 2013); secondly it has been applied as a soil amendment because it can regulate the soil physical, chemical and biological properties, while improve the soil moisture conditions, thereby providing a good soil environment for crop growth (Gond et al. 2013, Zaady et al. 2017, Wu et al. 2018). Pathan et al. (2003) indicated that the hydraulic conductivities in the fly ashes were 105- to 248-fold slower than that in the coarse sand, and the water-holding capacities of fly ashes at field capacity were three times higher than those in the coarse sand. Yunusa et al. (2006) showed that the addition of fly ash to sand can effectively reduce the soil hydraulic conductivity. Ghodrati et al. (1995) showed that with 30\% fly ash, saturated hydraulic conductivity of sand was reduced by $80 \%$, and field capacity was increased by about 1 time. Kalra et al. (2000) indicated that the moisture retained at field capacity increased by $295.7 \%$ compared to sand when the fly ash content was $40 \%$. Therefore, it would be feasible to use the rich fly ash resources to construct an artificial plow pan to achieve the purpose of supporting water and fertilizer in paddy soil.

In the present study, water characteristics of the artificial plow pan constructed by mixing the fly ash to sandy soil were determined to find the best plow pan structure and to suggest its use in the land improvement of the Yellow River beach.

\section{Materials and Methods}

The sandy soil used in the experiment material was taken from Xiayukou Hancheng City, and fly ash was taken from Hancheng Power Plant. Experimental materials were air-dried after removing debris, then ground and passed through a 2-mm sieve. The mechanical composition of the materials was measured using a MS2000 laser particle size analyzer (Malvern Instruments Ltd., Malvern, United Kingdom). pH was measured using a 1:2.5 soil-water ratio extraction method and an S220 acidometer (Mettler Toledo Instruments Ltd., Zurich, Switzerland). The basic physicochemical properties of the materials are presented in Table 1.

The plow pan layer was designed to have three bulk density with two different mixing ratios by weight (Table 2). Pure sandy soil was used as a control (CK) under each group of treatments. Each treatment was repeated 3 times.

Table 1. Basic physical and chemical properties of experimental material.

\begin{tabular}{|c|c|c|c|c|c|}
\hline \multirow[t]{2}{*}{$\begin{array}{l}\text { Experimental } \\
\text { material }\end{array}$} & \multirow[t]{2}{*}{$\mathrm{pH}$} & \multicolumn{3}{|c|}{$\begin{array}{l}\text { Particle-size distribution } \\
\qquad(\%)\end{array}$} & \multirow[t]{2}{*}{ Soil texture } \\
\hline & & Clay $(0-2 \mu \mathrm{m})$ & Silt $(2-50 \mu \mathrm{m})$ & Sand $(50-2000 \mu \mathrm{m})$ & \\
\hline Sandy soil & 8.71 & 0.89 & 4.41 & 94.70 & Sand \\
\hline Fly ash & 9.13 & 2.53 & 29.60 & 67.87 & Sandy loam \\
\hline
\end{tabular}

A cylindrical one-dimensional water infiltration test was used. The testing device consisted of a plexiglass column with a height of $45 \mathrm{~cm}$ and an inner diameter of $10 \mathrm{~cm}$ and a 50 liters water bottle. The bottom of the soil column had small holes of different sizes (diameters varying from 0.05 to $0.2 \mathrm{~cm}$ ), the upper layer was covered with gauze, and the gauze was filled with $10 \mathrm{~cm}$ of each treated soil sample mixed with fly ash and sandy soil as the plow pan. The upper part of the plow pan was filled with sandy soil with a bulk density of $1.7 \mathrm{~g} \mathrm{~cm}^{-3}$ and the total soil height was $40 \mathrm{~cm}$. Water was supplied to the soil column using a Markov bottle to maintain a $3 \mathrm{~cm}$ stable 
head height. The movement of the wetting front was recorded at the beginning of the test. After the infiltration test, the Markov bottle was continuously supplied with water. When the soil column was saturated, the hydraulic conductivity was measured. At the end of the test, soil samples were taken every $5 \mathrm{~cm}$ to determine the water content of each layer, and to calculate the water storage capacity.

Table 2. Experimental treatment.

\begin{tabular}{ccc}
\hline Treatment & $\begin{array}{c}\text { Bulk density } \\
\left(\mathrm{g} / \mathrm{cm}^{-3}\right)\end{array}$ & $\begin{array}{c}\text { Fly ash: sandy soil } \\
(\mathrm{w} / \mathrm{w})\end{array}$ \\
\hline A1 & 1.65 & $\mathrm{CK}$ \\
A2 & & $1: 3$ \\
A3 & & $1: 2$ \\
B1 & 1.7 & $\mathrm{CK}$ \\
B2 & & $1: 3$ \\
B3 & & $1: 2$ \\
C1 & 1.8 & $\mathrm{CK}$ \\
C2 & & $1: 3$ \\
C3 & & $1: 2$ \\
\hline
\end{tabular}

\section{Results and Discussion}

Variation of the movement depth of the wetting front with time showed that the control movement rate was very fast (Fig. 1). The advancement time of the wetting fronts of A1, B1 and C1 reaching $40 \mathrm{~cm}$ profile bottom was only 9,15 and $20 \mathrm{~min}$ and the initial wetting front movement rate was reduced from $5.2,4.8,3.6$ to $2.0,1.0,0.7 \mathrm{~cm} / \mathrm{min}$, respectively at the bottom. Compared to the same bulk density treatments, the initial movement rate was basically the same. With the same bulk density, the initial movement rate was in the order of A2 > A3, B2 > B3 and $\mathrm{C} 2>\mathrm{C} 3$. The proportion of fly ash application, the smaller the initial movement rate. The final rate at $40 \mathrm{~cm}$ showed the same trend. Under the same filling bulk density, the average movement rate of each treatment in the plow pan layer were in the order of A2 $>$ A3, B2 $>$ B3 and C2 $>$ C3, which also showed that the larger the proportion of fly ash, the smaller the average movement rate. In the same bulk density treatment, the wetting front movement time to the $40 \mathrm{~cm}$ bottom of A2 and A3 were 35.6 and 37.8 times than that of control A1; B2 and B3 were 23.3 and 24.0 times than that of control B1; C2 and C3 were 18.0 and 20.0 times than that of control C1.

Compared to the treatment with same fly ash application and different bulk density, the initial, average and final movement rate in the plow pan were in the order $\mathrm{A} 2>\mathrm{B} 2>\mathrm{C} 2$ and $\mathrm{A} 3>\mathrm{B} 3>$ $\mathrm{C} 3$, respectively. From $25 \mathrm{~cm}$, the wetting front movement rate showed a significant difference (Fig. 1), probably due to the blockage of the artificial plow pan layer formed by the fly ash and sand at $30 \mathrm{~cm}$. Each treatment showed that with the fly ash application rate the bulk density increased, the movement depth of the wetting front in the plow pan reduced at the same time. The results indicated that the addition of the fly ash in this region can effectively reduce the water infiltration rate and improve the hydraulic movement characteristics of the sandy soil. 


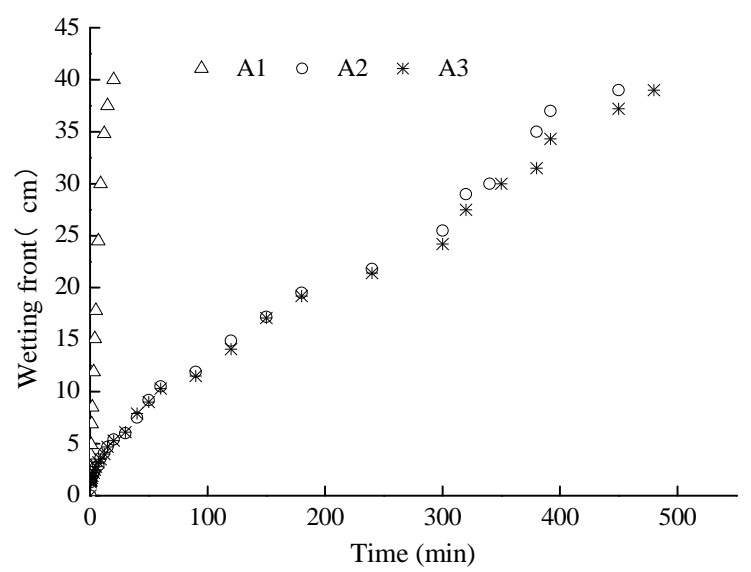

a. Different fly ash addition amount with the bulk density of $1.65 \mathrm{~g} / \mathrm{cm}^{3}$.

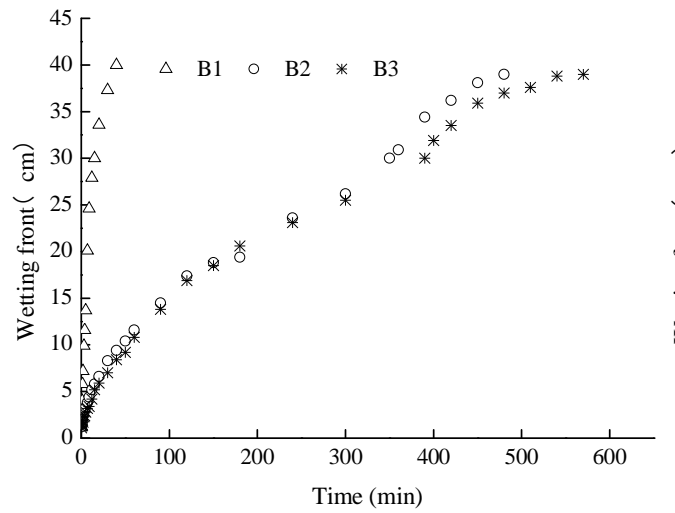

b. Different fly ash addition amount with the bulk density of $1.7 \mathrm{~g} / \mathrm{cm}^{3}$.

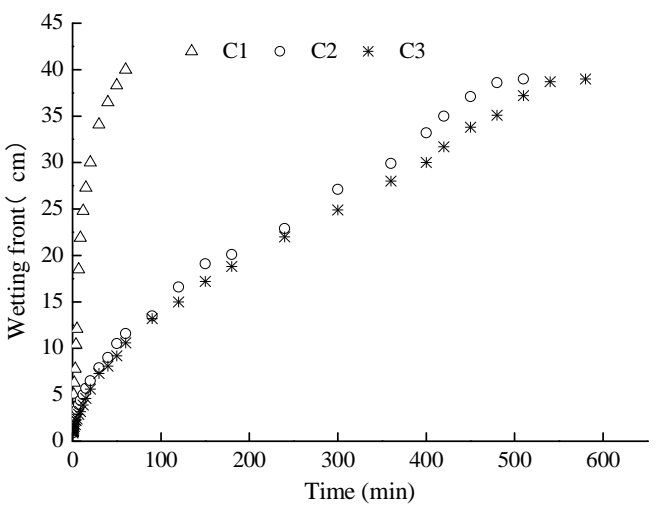

c. Different fly ash addition amount with the bulk density of $1.8 \mathrm{~g} / \mathrm{cm}^{3}$.

Fig. 1. Variation of the movement depth of the wetting front with time.

Saturated hydraulic conductivity is an important parameter of soil water movement, which can reflect soil leakage and infiltration properties, and has important significance in agricultural water and soil engineering (Lin 2010, Jarvis et al. 2013, Vereecken et al. 2015, Xu et al. 2017). In the present study, the saturated water conductivity of the control treatment was the highest (Fig. $2 \mathrm{a})$. When the control sand was compacted, the saturated hydraulic conductivity was reduced, but there was no significant difference between the treatments before and after compaction. Compared to the saturated hydraulic conductivity of the same amount of fly ash and different compacted bulk density treatments (Fig. 2b, c), C2 was 6.1 and 20.7\% lower than B2 and A2, and C3 was 14.0 and $30.2 \%$ lower than $\mathrm{B} 3$ and $\mathrm{A} 3$, respectively. As the compacted bulk density increased, the saturated hydraulic conductivity decreased. After the addition of fly ash, the saturated hydraulic conductivity of each treatment under the same bulk density was reduced by about 4 orders of magnitude compared to the control (Fig. 3). When compared the saturated hydraulic conductivity of the two treatments with different amount of fly ash added and had the same bulk density, A3 was about $8.6 \%$ less than A2, B3 was about $12.2 \%$ less than B2, and C3 was about $19.6 \%$ less than $\mathrm{C} 2$. This showed that the addition of fly ash significantly reduced the saturated hydraulic 
conductivity of each treatment, indicating that the more the amount of fly ash was added, the smaller was the saturated hydraulic conductivity. The results indicated that the fly ash can improve the hydraulic properties of strong permeable sandy soil and increase crop water supply.

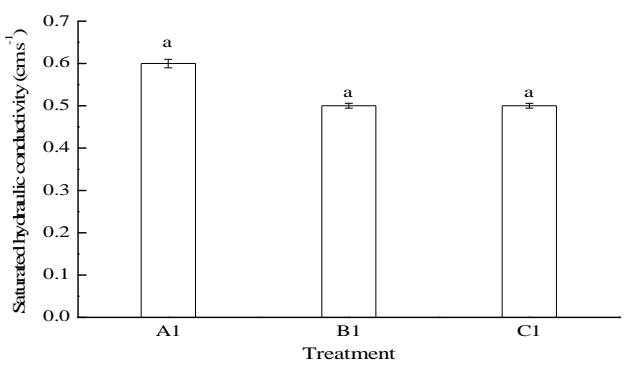

a. Sand soil with different bulk density.

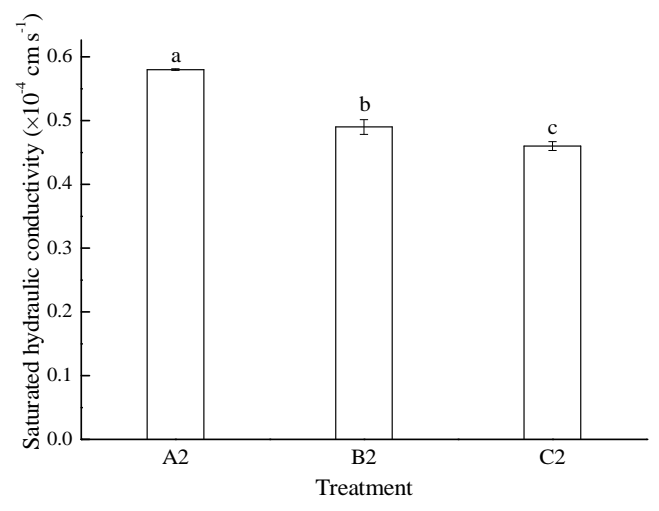

b. The ratio of fly ash to sandy soil was $1: 3$ for different bulk density.

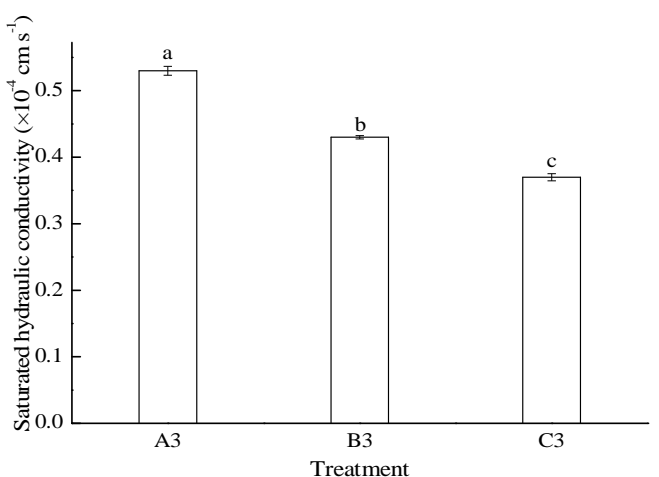

c. The ratio of fly ash to sandy soil was 1:2 for different bulk density.

Fig. 2. Saturated hydraulic conductivity of different bulk density treatment. Different letters at the top of the bars indicated a significant difference in saturated hydraulic conductivity among the same fly ash addition amount with different bulk density $(\mathrm{p}<0.05)$.

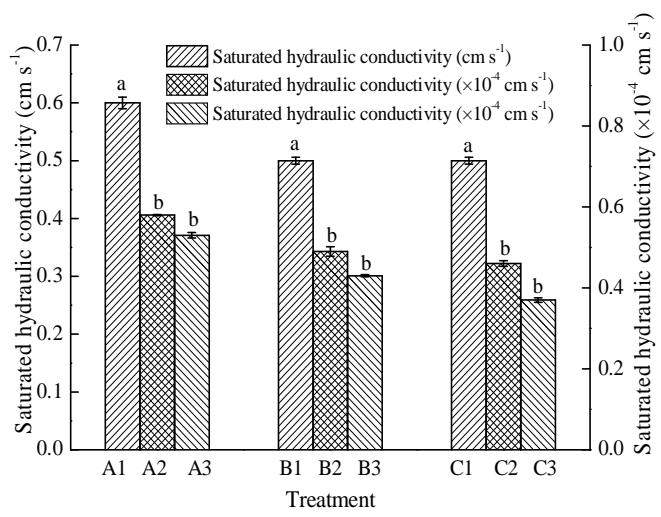

Fig. 3. Saturated hydraulic conductivity at different fly ash addition amount treatments. Different letters at the top of the bars indicated a significant difference in saturated hydraulic conductivity among the same bulk density with different fly ash addition amount $(\mathrm{p}<0.05)$. 
The soil water content did not change significantly above $20 \mathrm{~cm}$ deep soil layer, and has a certain improvement in 20-30 cm deep (Fig. 4). It showed that soil water content increased with the addition of fly ash. The increasing trend might be caused by the retardation of soil moisture by the addition of fly ash. The addition of fly ash significantly affected the soil water distribution. The soil water content of the plow pan $(30-40 \mathrm{~cm})$ constructed by fly ash and sand was significantly higher than that of the control. Comparing the average water content of plow pan, A2 and $\mathrm{A} 3$ were 1.29 and 1.33 times of $\mathrm{A} 1, \mathrm{~B} 2$ and $\mathrm{B} 3$ were 1.31 and 1.33 times of $\mathrm{B} 1$, and $\mathrm{C} 2$ and $\mathrm{C} 3$ were 1.30 and 1.32 times of $\mathrm{C} 1$, respectively.
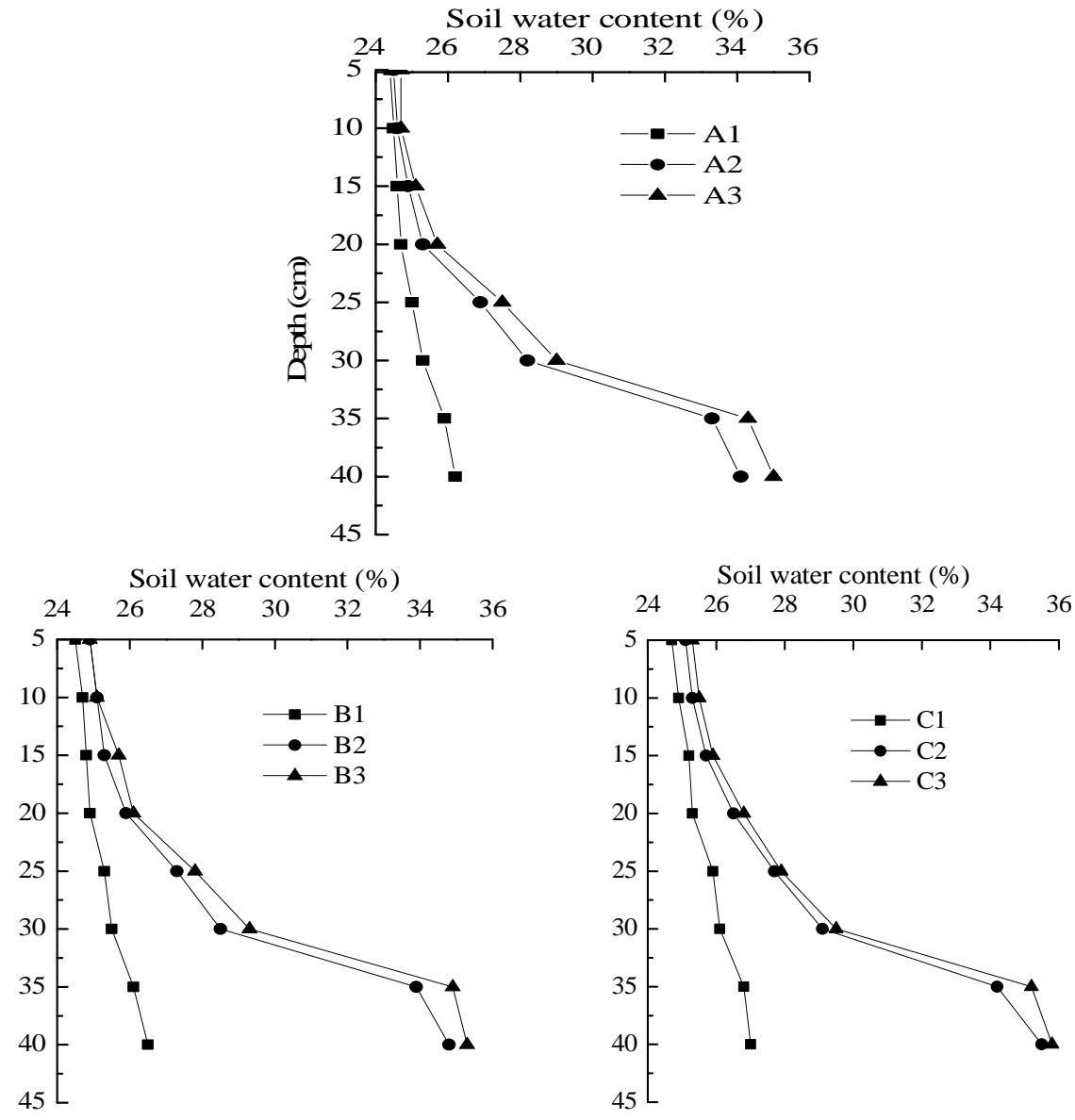

Fig. 4. Soil water content in different soil depths.

The water storage capacity of the plow pan constructed by adding fly ash was analyzed according to the vertical distribution characteristics of water content. It showed that under the same bulk density, the soil water storage capacity of each treatment was significantly improved compared to control (Fig. 5). The results fully confirmed the feasibility of adding fly ash to construct plow pan of paddy soil in the Yellow River beach. It can play a significant role in supporting water and fertilizer than the original sandy soil. 


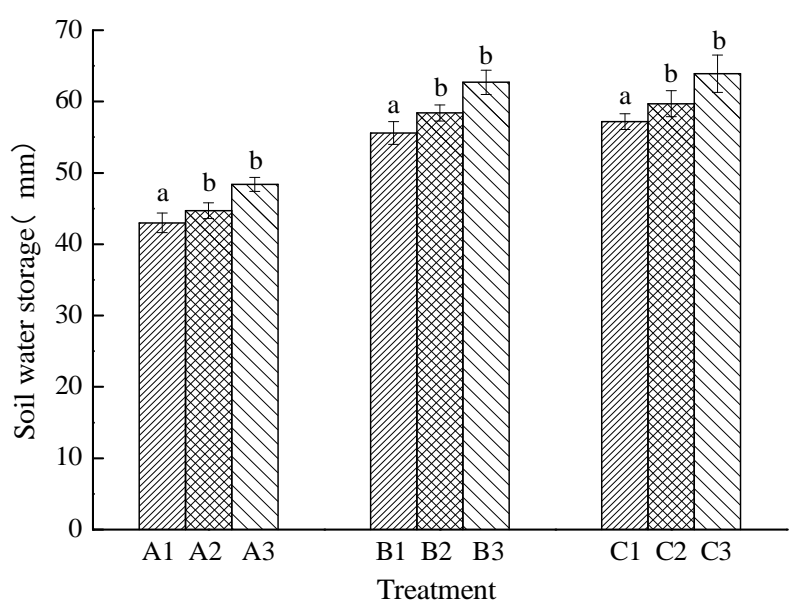

Fig. 5. Soil water storage capacity of artificial plow pan. Different letters at the top of the bars indicated a significant difference in soil water storage capacity between the same bulk density with different fly ash addition amount $(\mathrm{p}<0.05)$.

The plow pan of the high-yield paddy soil should have suitable bulk density, certain water conductivity, and proper water and fertilizer retention characteristics. The extremely low or high bulk density has been found to be the limiting factor for high yield of rice. When the plow pan bulk density was $1.7 \mathrm{~g} \mathrm{~cm}^{-3}$, the soil active reducing substances in the rice growing season increased correspondingly, the root activity was significantly enhanced, and the biomass was the maximum (Xiao et al. 1996). The plow pan saturated hydraulic conductivity of high-yield paddy soil cultivated for many years was between $0.45 \times 10^{-4}-1.47 \times 10^{-4} \mathrm{~cm} / \mathrm{s}$ (Zhang et al. 2011). It could be concluded that B2 treatment $\left(1.7 \mathrm{~g} / \mathrm{cm}^{3}\right.$, fly ash: sand $\left.=1: 3\right)$ can best meet the bulk density and water conductivity requirements of the paddy soil plow pan.

Effects of fly ash application on plow pan water characteristics indicated that the addition of the fly ash in this region can effectively improve the hydraulic movement characteristics of the strong permeable sandy soil and increase crop water supply. Results confirmed the feasibility of adding fly ash to construct plow pan of paddy soil in the Yellow River beach. Comparing the mechanical composition of fly ash in different regions, most of the fly ash was found to have the highest content of silt (67 72\%), followed by sand (25 30\%) and the smallest clay (Zhao and Tang 2009, Hartmann et al. 2010, Li et al. 2011, Zhao et al. 2013a, 2013b, Zaady et al. 2017). Therefore, fly ash can effectively improve the sand texture and can effectively change the poor water physical properties of sandy soil. Fly ash also has a strong water absorption capacity because of its porous honeycomb structure with a large surface area and surface tension (Yoo and Jo 2003, Kalinski and Yerra 2006, Kamata and Yukimura 2012, Mishra 2013, Qin et al. 2015, Song et al. 2016). At the same time, the fly ash surface has a large number of Si-O-Si bonds, and after interaction with water, there will be a large amount of hydroxyl groups on the surface, showing significant hydrophilicity and adsorption (Yang et al. 1997, Jia et al. 2018). Yang et al. (1997) reported that the maximum moisture absorption of fly ash was about $6.35 \mathrm{~g} / \mathrm{kg}$, the maximum water absorption was about $727.5 \mathrm{~g} / \mathrm{kg}$ on average, and the water absorption capacity was roughly equivalent to that of soil. Therefore, the use of fly ash to improve sandy soil significantly enhanced the sandy soil water holding capacity. By adding fly ash to the sandy soil, the plow pan of the paddy soil could be constructed, and the purpose of planting rice in the beach land of Yellow River can be achieved. 
In the present study, the best artificial plow pan construction in paddy soil was determined by measuring the water characteristics of soil. The water characteristics were noticeably influenced by fly ash. Due to the admixture of fine texture and hydrophilic fly ash, the artificial plow pan featured a distinct decrease in permeability and saturated hydraulic conductivity, and the soil water content was noticeably increased. It may be concluded that it would be feasible to use fly ash and sandy soil to construct the plow pan of paddy soil in this region. The ideal plow pan configuration was that the fly ash and the sand should be mixed in a mass ratio of 1:3, and the bulk density was $1.7 \mathrm{~g} / \mathrm{cm}^{3}$. Through the present work the most suitable physical configuration of the paddy soil has been obtained, but the soil nutrients were relatively inferior. In the subsequent research and practical work, continuous improvement of soil fertility is needed to achieve high rice yield.

\section{Acknowledgements}

The authors are grateful for financial support from Shaanxi Province Key R\&D Project (2019SF-245), Technology Innovation Center for Land Engineering and Human Settlements, Shaanxi Land Engineering Construction Group Co. Ltd. and Xi'an Jiaotong University (2021WHZ0094) and Research Project of Shaanxi Provincial Land Engineering Construction Group in China (DJNY2020-19) for this study.

\section{References}

An CJ, Yang SQ, Huang GH, Zhao S, Zhang P and Yao Y 2016. Removal of sulfonated humic acid from aqueous phase by modified coal fly ash waste: equilibrium and kinetic adsorption studies. Fuel 165: 264-271.

Dunea D and Dinca N 2014. Improving land utilization using intensive grass-clover mixtures in forage production systems. Rom. Agric. Res. 31(31): 1-12.

Gao LH and Goldfarb JL 2019. Heterogeneous biochars from agriculture residues and coal fly ash for the removal of heavy metals from coking wastewater. Res. Adv. 9:16018-16027.

Ghodrati M, Sims JT and Vasilas BL 1995. Evaluation of fly ash as a soil amendment for the Atlantic Coastal Plain: I. Soil hydraulic properties and elemental leaching. Water Air Soil Poll. 81(3-4): 349-361.

Gond DP, Singh S, Pal A and Tewary B 2013. Growth, yield and metal residues in Solanum melongena grown in fly ash amended soils. J. Environ. Biol. 34(3): 539-544.

Hartmann P, Fleige H and Horn R 2010. Changes in soil physical properties of forest floor horizons due to long-term deposition of lignite fly ash. J. Soil. Sediment. 10(2): 231-239.

Jarvis N, Koestel J, Messing I, Moeys J and Lindahl A 2013. Influence of soil, land use and climatic factors on the hydraulic conductivity of soil. Hydrol. Earth. Syst. Sc. 17(12): 5185-5195.

Jia YF, Feng HJ, Shen DS, Zhou YY, Chen T, Wang MZ, Chen W, Ge ZP, Huang LJ and Zheng ST 2018. High-performance microbial fuel cell anodes obtained from sewage sludge mixed with fly ash. J. Hazard. Mater. 354(15): 27-32.

Kalinski ME and Yerra PK 2006. Hydraulic conductivity of compacted cement-stabilized fly ash. Fuel 85(16): 2330-2336.

Kalra N, Harit RC and Sharma SK 2000. Effect of fly ash incorporation on soil properties of texturally variant soils. Bioresource Technol. 75(1): 91-93.

Kamata $\mathrm{H}$ and Yukimura A 2012. Catalyst aging in a coal combustion flue gas for mercury oxidation. Fuel Process. Technol. 104: 295-299.

Li ZH, Bai SD, Cui ZY and Gao J 2011. Study on improved physical properties of aeolian sandy soil with fly ash. J. Anhui Agr. Sci. 39(36): 22399-22400.

Lin H 2010. Earth's Critical Zone and hydropedology: concepts, characteristics, and advances. Hydrol. Earth Syst. Sc. 14(1): 25-45. 
Liu KX and Liao ZW 1997. Agriculture exploitation for fly ash and its significance. Fly Ash Compr Util. 1: 44-46.

Maebana MO, Mishra SB, Mamba BB and Mishra AK 2013. Study on the efficiency of ethylene vinyl acetate-fly ash composites for the uptake of phenols from synthetic waste water. J. Appl. Polym. Sci. 128: 2073-2080.

Medina R, Menezes GB, Khachikian CS and Ellis A 2015. Use of fly ash as soil amendment to offset anion exclusion effect on nitrate transport. Vadose Zone J. 14(4): 1-9.

Mishra R 2013. Specific functional properties of 3D woven glass nanocomposites. J. Compos. Mater. 48(14): $1745-1754$.

Niels $\mathrm{OH}$ 2015. Agreement based land consolidation-in perspective of new modes of governance. Land Use Policy 46: 163-177.

Pathan SM, Aylmore LA and Colmer TD 2003. Properties of several fly ash materials in relation to use as soil amendments. J Environ Qual 32(2): 687-693.

Qin Q, Wang JM, Wang HD, Li XF and Zhu YC 2015. The comparative study of hydraulic characteristics under different filling medium on coal mining subsided land. China Coal 41(2): 114-119.

Qiu Q and Hlavacek V 2010. Energy estimation on CRN process of fly ash as a slow release nitrogen fertilizer. Ind. Eng. Chem. Res. 49(12): 5939-5944.

Sano T, Miura S, Furusawa H, Kaneko S, Yoshida T, Nomura T and Ohara S 2013. Composition of inorganic elements and the leaching behavior of biomass combustion ashes discharged from wood pellet boilers in Japan. J. Wood Sci. 59(4): 307-320.

Song YR, Wang JM, Li XF, Wu KN and Bai ZK 2016. Simulation of moisture transfer law with different soil reconstruction models in coal mining subsided area with high ground-water level. J. Soil Water Conser. 30(2): 143-148.

Tang X, Pan Y and Liu Y 2017. Analysis and demonstration of investment implementation model and paths for China' cultivated land consolidation. Appl. Geogr. 82: 24-34.

Ukwattage NL, Ranjith PG, Bouazza M 2013. The use of coal combustion fly ash as a soil amendment in agricultural lands (with comments on its potential to improve food security and sequester carbon). Fuel 109: 400-408.

Vereecken H, Huisman JA, Franssen HJH, Brüggemann N, Bogena HR, Kollet S, Javaux M, Kruk JVD and Vanderborght J 2015. Soil hydrology: Recent methodological advances, challenges, and perspectives. Water Resour. Res. 51(4): 2616-2633.

Wang YD, Li TX, Xia JG and Gu XW 2001. The development and utilization of river-beach land resources in Pengzhou City. J. Sichuan Agric. Univ. 19: 58-61.

Wu H, Zhu Y, Bian S, Ko JH, Sfy L and Xu Q 2018. H2S adsorption by municipal solid waste incineration (MSWI) fly ash with heavy metals immobilization. Chemosphere 195: 40-47.

Xiao CM, Ke YS, Huang JM, Lun XJ and Jiang HF 1996. Study on the influence of the bulk density of plowing layer on rice growth. Guangdong Agr. Sci. 2: 25-28.

$\mathrm{Xu} \mathrm{CH}$, Xu XL, Liu MX, Liu W, Yang J, Luo W, Zhang RF and Kiely G 2017. Enhancing pedotransfer functions (PTFs) using soil spectral reflectance data for estimating saturated hydraulic conductivity in southwestern China. Catena 158: 350-356.

Yang JH, Che FC, Wang DY, Xie DT, Wei CF and Zhang L 1997. Study on physical and chemical properties of fly ashes and their agrochemical behaviours. J. Plant Nutr. Fertil. 3(4): 341-348.

Yoo JG and Jo YM 2013. Utilization of coal fly ash as a slow-release granular medium for soil improvement. J. Air Waste Manage. 53(1): 77-83.

Yunusa IAM, Eamus D, Desilva DL, Murray BR, Burchett MD, Skilbeck GC and Heidrich C 2006. Fly-ash: An exploitable resource for management of Australian agricultural soils. Fuel 85(16): 2337-2344.

Zaady E, Katra I, Barkai D, Knoll Y and Sarig S 2017. The coupling effects of using coal fly-ash and bioinoculant for rehabilitation of disturbed biocrusts in active sand dunes. Land Degrad. Dev. 28: 12281236. 
Zhang Y, Chen XM and Lin H 2011. Hydraulic characteristics and soil reservoir capacity of typical paddy soil in Taihu Lake region. Bull. Soil Water Conserv. 31(5): 64-67.

Zhao L and Tang ZJ 2009. Effect of soil physical properties using fly ash as sandy soil amendment. J. Soil Water Conserv. 23(6): 178-181.

Zhao Z, Tang ZJ, Song MG and Yang K 2013a. A field trial of polyacrylamide and fly ash for modifying physical properties of sandy soil. J. Soil Water Conserv. 27(3): 178-183.

Zhao Z, Tang ZJ, Yang K, Liu JQ and Xu L 2013b. Metal transportation and accumulation in sandy soil amended by fly ash and PAM. T. Chin. Soc. Agric. Mach. 44(7): 83-89.

(Manuscript received on 22 July, 2021; revised on 30 September, 2021) 